\title{
Trust, Transparency and Security in the Sharing Economy: What is the Government's Role?
}

\author{
Ruben D’Hauwers, Jacobus van der Bank, Mehdi Montakhabi
}

\author{
"Power, today, comes from sharing information. Not \\ withholding it." \\ Keith Ferrazzi \\ Author \& Entrepreneur
}

\begin{abstract}
To obtain access to goods or services between people or stakeholders, some collaboration between actors is a necessary component. Sharing and a sharing economy is closely related to trust. Within the context of "the" sharing economy, especially digital trust is assumed to play a crucial role. Access to information is a crucial digital cue which can lead to trust yet, sharing economies are subject to asymmetry of information, wherein certain actors have limited access to market information on the consumption behaviour of users, the pricing of a product and, the reliability of peers. The lack of confidential market information between actors is thus limiting the potential for collaboration, as it reduces trust between them. Governments are amongst the (usually more trustworthy) candidates to undertake critical roles in enhancing the sharing of sensitive data. This paper aims to identify the role of government in facilitating and enabling data sharing between various actors in sharing economies. In this paper, we analyse the adequacy of a government's potential role in enabling transparency, trust and security, while operating within a sharing economy scenario, based on two case studies. Additionally, the role of technology is briefly defined for digital platforms and for blockchain-based opportunities for sharing economies. The use cases for the paper concern a digital platform for industrial symbioses, and peer-to-peer electricity trading based on blockchain technology.
\end{abstract}

\section{Introduction}

If a person wants to share their car, trust is required that the person using the car will 1) take care of the car, 2) will not steal or damage the car, and 3) that this person will pay for their usage of the car. The actor borrowing their car needs to trust that the car is in good shape and that the car will be available at the required time.

Peer-to-peer (P2P) markets, goods and services sharing, and the "sharing economy" are closely related to trust (Belk, 2010). Within the context of sharing economies, trust is assumed to play a crucial role (Botsman \& Rogers 2010; Mazella, 2016). Thus, trust within a sharing economy is of crucial importance in order to enable sharing economy transactions to occur.
Governments play an important role in ensuring the functioning of our societies (Zucker, 1986; Möhlman, 2018). This paper therefore seeks to better understand the implications, potential advantages, and disadvantages when governments take on certain roles towards or within the sharing economy. The paper will answer the following question: What is the role of governments in sharing economies to help ensure trust between users? In order to deepen this research question, the paper will elaborate on what the role of technology can be to ensure that government plays a role in ensuring trust in sharing economies.

This paper contributes to policymaking by identifying the options governments have to build trust in sharing economies. In order to elaborate on the role of governments in ensuring trust for sharing economies, 


\section{Trust, Transparency and Security in the Sharing Economy: What is the Government's Role? Ruben D'Hauwers, Jacobus van der Bank, Mehdi Montakhabi}

we applied the above research question on two distinct use cases. A major challenge that governments have, we found, is ensuring that the government itself can be trusted. If a conflict arises where the government can take up the role of serving as a facilitator of trust, while also being a regulator of it, the trust might be lost. Governments can overcome this trust issue with their citizens by defining their role clearly. Additionally, they can make use of technological advancements, such as blockchain and digital platforms, to help mitigate the lingering distrust of citizens and their governments, as a way of exploring the logic and use of sharing economies.

The paper is organised as follows. The upcoming section reviews the background and works related to trust issues and their importance in shaping sharing economies. The following section introduces the methodology used in this study, and following that is a description of two case studies. The next section discusses takeaways from two case studies in answer to the main research question, and introduces the limitations of this study. Finally, a short conclusion is offered, as well as identifying opportunities for future research.

\section{Background and Related Work}

\section{Sharing Economies}

A sharing economy is often referred to as a collaborative economy, one that functions with collaborative consumption, on-demand economy, ondemand services. It is also known as a gig economy, freelance economy, peer economy, access economy, crowd economy, digital economy, and platform economy (Botsman, 2015; Rinne, 2017). In what is now widely referred to as "the sharing economy", temporary access is granted to under-utilised physical assets, possibly money (Belk, 2014; Frenken et al., 2015; Rinne, 2017). The sharing economy can enable both individuals and businesses to exchange goods, services, resources, skills, or money (Nationale Bank België, 2020), by instilling a collaboration-oriented ethos.

P2P economy is a decentralized model whereby two or more individuals interact to buy and sell goods and services directly with each other, or to produce goods and services together (Investopedia, 2020). A P2P market is a market where individuals can share already-used or under-utilized possessions with other individuals. It is an economic model with $\mathrm{P} 2 \mathrm{P}$-based activities of acquiring, providing, and sharing access to goods and services, often facilitated through a digital platform (Hamari et al., 2015). The goal of P2P markets is to create trade between large numbers of separate distinct buyers and sellers.

\section{Trust in Sharing Economies}

Trust can be defined from numerous standpoints. The economic standpoint considers trust as a method of 'implicit contracting' for certain transactions. An implicit contract is an understanding between parties about acceptable forms of behaviour that is not part of any formal agreement. (Möhlman et al., 2018; Oxford Reference, 2020). Trust plays a key role in transaction cost economics (Williamson, 1993) and game theory (Dasgupta, 1988).

Verbeke and Greidanus (2012) introduce the bounded reliability concept and focus on safeguards rather than trust. In this view, trust is blind and there is no place for it in the marketplace. Safeguards are required because of the existence of bounded reliability (Kano \& Verbeke, 2015). Acute problems of bounded reliability enforce many business decisions rather than blind trust. For this reason, firms introduce safeguards or enforcement mechanisms to heighten detection of and provide punishment for reneging (Verbeke, 2013).

The sociological standpoint interprets trust as a more comprehensive concept, also capturing underlying framework conditions, such as personal character and the institutional settings in which individuals act (Zucker, 1986). The sociological standpoint looks at trust as a defining variable for human and business relationships. New forms of P2P trustless contracts can help to alleviate distrust and uncertainty in unsure environments (Luhman, 1979). Thus, developing trust is seen to be of crucial importance for sharing economies to overcome some of the complex uncertainties (Möhlmann, 2015, 2016, 2018).

Another standpoint is based on technology-mediated interactions (Riegelsberger et al., 2004). Currently, several value or asset transactions between users are performed over a distance with various technologies as supporting mechanisms. Thus, exchanges that previously would have been performed face-to-face are now happening through technological means. Trust in such cases can be related to attributes of the various trustees, or emerge on the design of the technology. 


\section{Trust, Transparency and Security in the Sharing Economy: What is the Government's Role? Ruben D'Hauwers, Jacobus van der Bank, Mehdi Montakhabi}

McKnight and Chervany's (2000) interdisciplinary model of trust is built on four trust constructs that are based on the attributes of a trustee. Having a disposition to trust reveals the tendency of a person or entity to be willing to depend on others. Second, the institution of trust shows whether an actor believes the needed conditions are in place for a successful outcome of an endeavor. Trusting beliefs are beliefs if another person has the confidence of desirable traits in a situation where negative outcomes are possible. And last, trusting intention is the willingness to depend on other actors in a given task or situation with a feeling of security. Than and Thoen (2000), describe trust for ecommerce as being based on party trust (trusting the other party), and control trust (trust in a controlled system with mediating technology). Corritore et al. (2003) examine online trust between people and transactional websites. Their model identifies three factors that impact online trust: perception of credibility, ease of use, and risk.

Riegelsberger et al. (2004) focus on technology design that can influence trustworthy behaviour in specific situations or contexts. Contextual properties (likeliness of future encounters, reputation, having friends in common, and institutional embeddedness) will create trust in a first interaction and encounter, while intrinsic properties of the trustee (ability, internalized norms, and benevolence) are more important in continued exchanges as trustor and trustee get to know each other.

\section{Information Needs in Sharing Economies}

Access to information is crucial for enabling sharing economies and P2P dynamics. Information can enable people to share different goods with each other. Yet, a sharing economy is subject to the asymmetry of information, where certain actors have limited access to market information on the consumption behaviour of users, the pricing of a product and, peer reliability (Cohen, 2014). Akerhof (1970) describes the issue of information asymmetry that prevents mutually beneficial exchanges from taking place. Pavlou and Gefen (2004) argue that individuals are less likely to trust an individual who retains an information advantage. Thus, while trust is important, if trustbuilding mechanisms are lacking, the market will suffer (Akerhof, 1970).

To facilitate trust, digital platforms can mediate trust by enabling trust enhancing digital cues (Möhlmann, 2016). An important digital que is the provision of information. Knowing the basis of information provided is of fundamental importance for developing trust in each other as mutual platform users (Hawlitschek et al., 2016; Mazzella et al., 2016). Thus, sharing information on the goods or services offered in a sharing economy helps in developing trust (Möhlmann et al., 2018). Another way of ensuring a person's digital reputation through repetition of services is peer rating, as it offers opportunities to both assess and access digital social capital (Mazella et al., 2016).

\section{Incentivising Data Sharing}

Mechanisms that can incentivise information sharing, and at the same time increase transparency are crucial for the optimal functioning of a sharing economy and $\mathrm{P} 2 \mathrm{P}$ ecosystem. In P2P markets, information is dispersed to those who should be matched and at what prices. So, an effective market must aggregate and enable access to information successfully (Einav et al., 2016)

Since the quality of information that can be drawn from data increases with the available amount and quality of data, businesses involved in the data economy have great interest in accessing data from other market players. Thus, data sharing is enabled by information technologies and through behavioural and business incentives to share data between different actors, both with and by governments. Considering the potential of sharing data, policy makers have already encouraged business-to-business (B2B) data sharing (Kerber, 2016; Wiebe, 2016; Drexl, 2017). Data sharing can thus be used to enable access to large, high-quality data sets. However, companies still appear to be reluctant to share their data with each other, due to issues involving distrust.

Entering the market recently, is a new system called "blockchain" in which a record of transactions made using "cryptocurrency" are maintained across several computers that are linked in a P2P network (Oxford, 2020) Blockchain appears as a promising "distributed ledger" technology to emancipate digital P2P networks, as it facilitates exchanges between actors without the need of (or as) an intermediary, thus eliminating control by any single player (DiFilipi, 2017). Blockchain is also often referred to as a trust-free technology (Beck et al., 2016). It offers a new potential to facilitate P2P interactions in the sharing economy that could lead to higher levels of trust and information accessibility (Sundararajan, 2016). Distributed ledger technology is to some degree suitable to replace trust by users in platform owners. Trust will instead depend on the 


\section{Trust, Transparency and Security in the Sharing Economy: What is the Government's Role? Ruben D'Hauwers, Jacobus van der Bank, Mehdi Montakhabi}

distributed development of trusted interfaces in blockchain-based sharing economy ecosystems (Hawlitschek et al., 2018) Blockchain automatically creates a consensually agreed, publicly available, and immutable record that is governed to mitigate trust issues system (Greiner \& Wang, 2015).

\section{Data Sharing and the Role of Governments}

Governments are amongst the (most trustworthy) candidates to undertake critical roles in enhancing trust in the sharing economy (Möhlmann, 2018). The literature describes different roles a government could play in facilitating a sharing economy.

A first role could be for governments to ensure society's functioning by providing institutional cues, which take the form of rules and regulations (Zucker, 1986). Shapiro (1987) refers to institutional trust as belief in the security of a situation, for instance, based on guarantees or security nets, or legally binding contracts between parties. Another role could be that of a 'Government as a Platform' (GaaP), where a government develops better services for the public digitally. To accomplish this, the government can be organized around shared components, APIs, standards and datasets (O'Reilly, 2011). It can also ensure open public data. Open data refers to public data that can be freely used, re-used, and redistributed by anyone (Open Data Handbook, 2020).

A government can also be the beneficiary of data, to ensure proper policy is made. Currently, the European Commission is introducing the concept of business-togovernment $(\mathrm{B} 2 \mathrm{G})$ data sharing. This is a collaboration in which a company or other private organisation makes its data (or insights) available to the public sector (local, regional, national, or EU). Last, governments can play the role of facilitator for innovations. An example is the "Amsterdam Sharing City" project. Different stakeholders work on the common goal of establishing Amsterdam as a "city that has sharing on its mind" (Amsterdam Sharing City, 2017).

Thus, the literature has discussed the role of regulation, the role of developing governmental services as a Government as a Platform (GaaP), and the role of opening governmental data. Additionally, a government can facilitate innovations in data storage and usage. One topic that lacks in the current literature is the role governments can play in ensuring that data between peers can be shared. Likewise lacking is how the role of government must be built to ensure trust between different stakeholders.

\section{Aim and Methodology}

This paper aims to identify the role of government in facilitating and enabling the sharing of data between different actors in a sharing economy. This leads to a general framework of trust, transparency and traceability between $\mathrm{B} 2 \mathrm{~B}, \mathrm{~B} 2 \mathrm{C}$ and $\mathrm{P} 2 \mathrm{P}$ within a sharing ecosystem.

Two descriptive case studies are presented to provide the context for the study. The first descriptive case study 'Digital platform in industrial symbiosis' deals with B2B information sharing and the role of government in creating an electronic platform to enable this. The second descriptive case study 'Blockchain in Peer-toPeer Energy Trading' deals with P2P electricity trading and the role of government in enabling the sharing of electricity. It deals with security and privacy constraints in a blockchain network. Both use cases involve the region of Flanders, Belgium.

\section{Case Studies}

\section{Case study 1: Digital platform in industrial symbiosis}

\section{Introduction}

Industrial symbiosis is the process by which waste or byproducts of an industry or industrial process become the raw materials or inputs for another (Christensen, 1992; Engbert, 1993; European Commission, 2018). It consists of exchanges of waste streams and byproducts among various entities. By collaborating, the collective benefit becomes greater than the sum of the individual benefits in acting alone. It operates as a commercial activity, as the different actors buy and sell the waste streams and byproducts from each other (Chertow, 2000).

An often-cited example of Industrial Symbiosis is the site of Kalundborg. This is where an industrial site connects various companies with pipes, enabling different companies to share groundwater, surface water and wastewater, steam, and electricity, and also to exchange a variety of residues that become feedstocks in other processes (Engbert, 1993).

\section{Challenges of Trust}

In order to enable industrial symbiosis, data about the byproduct is required, to assess the potential for symbiosis with other actors. An actor needs to be able to 


\section{Trust, Transparency and Security in the Sharing Economy: What is the Government's Role? Ruben D'Hauwers, Jacobus van der Bank, Mehdi Montakhabi}

assess the validity of a waste stream or by-product, in order to define:

-What is the waste stream or byproduct? Does it match their need?

-What is the chemical composition of the waste stream or byproduct? Does it match within the current production process? What would the cost be to adapt the current production process?

-What is the quantity of the waste stream or byproduct? Is it sufficient to cover current waste needs within the production process? Is it a continuous offer or is it a one-off offer?

-What transportation needs and costs are associated with the match?

To close these gaps, corporate operational data must be disclosed within supply chain networks. As well, data-driven and optimization solutions for an industrial symbiosis network should be further addressed (Tseng, 2017). The information which provides answers to the above questions are often confidential and might consist of company trade secrets. Thus, access to data over the entire value chain is limited, which is the main barrier for matching companies in B2B scenarios.

The reasons why information about waste streams and byproducts is limited include because it concerns sensitive information: 1 ) information about production processes can be competitive, 2) information about amounts can give indications of the volumes a company is currently selling, 3) information about pricing is sensitive in negotiation processes.

\section{Role of Governments}

In order to create transparency in the industrial symbiosis market, a Flemish governmental agency acted as an intermediary to enable market transparency, as it had a neutral and non-competitive role in the ecosystem. The agency developed a digital matchmaking platform where users could identify other users, offering or receiving waste streams or byproducts. See figure 1 for the platform's ecosystem.

Companies could identify information on the product, on the chemical composition, the amounts to offer, and on the continuity of the waste stream (one-off or continuous). Thus, the platform offered a staged privacy setting, where companies could decide which information is visible or not at different levels. During private conversations, access to information could be disclosed with a trusted other party. Initially, nonsensitive data could be shared, followed by more sensitive information at later stages of the negotiation between the users.

When operationalising the platform, various issues of trust were identified. Between themselves, companies often do not wish to share information with each other if they are in competitive interactions. In these cases, the privacy settings were utilised in order to ensure no

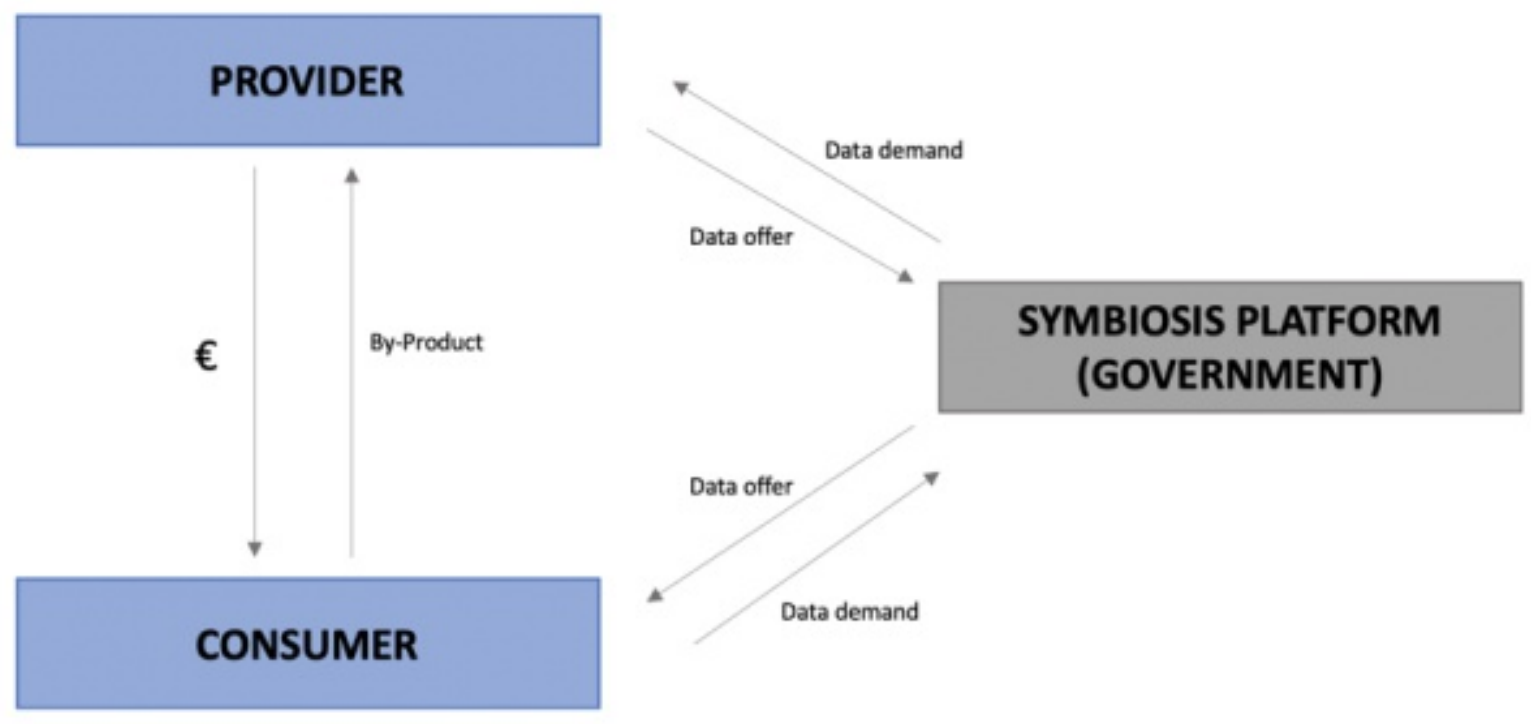

Figure 1. The ecosystem of a digital symbiosis platform 


\section{Trust, Transparency and Security in the Sharing Economy: What is the Government's Role? Ruben D'Hauwers, Jacobus van der Bank, Mehdi Montakhabi}

competitive information could be shared between competitors.

\section{Trust in Government}

There were some important considerations (pros and cons) we found in observing the government's role as a facilitator of trust in the sharing economy:

\section{PRO}

-The government has a neutral role in the ecosystem, as a facilitator. The key performance indicators (KPIs) of the government involve increasing the number of transactions, without wanting to have the main share or control access to independent data

-The government does not have a particular economic motivation

\section{CON}

-There is a mismatch between the role of a regulator and the role of a facilitator. As the government acts as a regulator, companies do not always trust sharing information with its agencies

-Companies dislike that their national government has access to sensitive information, which could be used for regulatory purposes

\section{Can Technology Mitigate the Lack of Trust?}

We found that if the government would get access to sensitive information which might lead to new policies or legal actions, then companies were not inclined to share the information. Therefore, an independent person not employed by the government was appointed to handle the data. The governmental agency did not have access to the data, in order to ensure the privacy concerns of the companies were covered. The technology supporting the service was a digital matchmaking platform that enabled privacy settings where certain information could be hidden while browsing. Upon request, specific information could be opened up in order to facilitate and enable transactions. The Flemish government allocated resources for building the platform and for human resources to maintain it, while paying an independent person to handle the data.

\section{Case study 2: Peer-to-peer electricity trading}

\section{Introduction}

Traditionally, electricity grids have been fed by the concentrated generation of electricity from power plants (coal, gas, nuclear, etc.). However, the availability of lowprice solar panels and batteries has made it possible to produce electricity dispersedly at prosumers' (consumers who can also act as producers) sites. This has created a lag between the production and consumption of electricity.

Smart meters (SMs) are nowadays widely installed at connection nodes and come with the option of finegrained metering and bidirectional communication. This has made it possible for prosumers (consumers with renewable energy sources [RES] and batteries) to have a surplus of electricity which could be injected into the grid and traced via the use of SMs. This surplus generated by the prosumer has been fed into the distribution grid (for free or for a fee) until recently.

Electricity markets are now slowly entering a new generation of electricity trading with $\mathrm{P} 2 \mathrm{P}$ electricity trading (Montakhabi et al., 2020). P2P electricity trading is an opportunity for prosumers to trade/share the surplus of electricity produced from renewable energy sources (RES) at their premises with each other (either directly or through an intermediary).

\section{Challenges of Trust}

Although P2P electricity trading could bring financial benefits to prosumers and environmental benefits in general, it may also create an opportunity for some entities to misbehave as a way to reduce costs or maximise profit. Impersonation, data manipulation, eavesdropping, privacy breaches, disputes, and denialof-service (DoS) are amongst potential security/privacy threats. Security and privacy considerations are amongst the most serious constraints for P2P electricity trading (Mustafa et al., 2017).

P2P electricity trading imposes some inevitable changes in the value network of the electricity market. New activities are required, and two new roles emerge, namely, representatives and brokers (Montakhabi et al., 2020). The activities taken up by representatives and brokers require them to have access to sensitive user data. An important question that then arises is "Who is 


\section{Trust, Transparency and Security in the Sharing Economy: What is the Government's Role? Ruben D'Hauwers, Jacobus van der Bank, Mehdi Montakhabi}

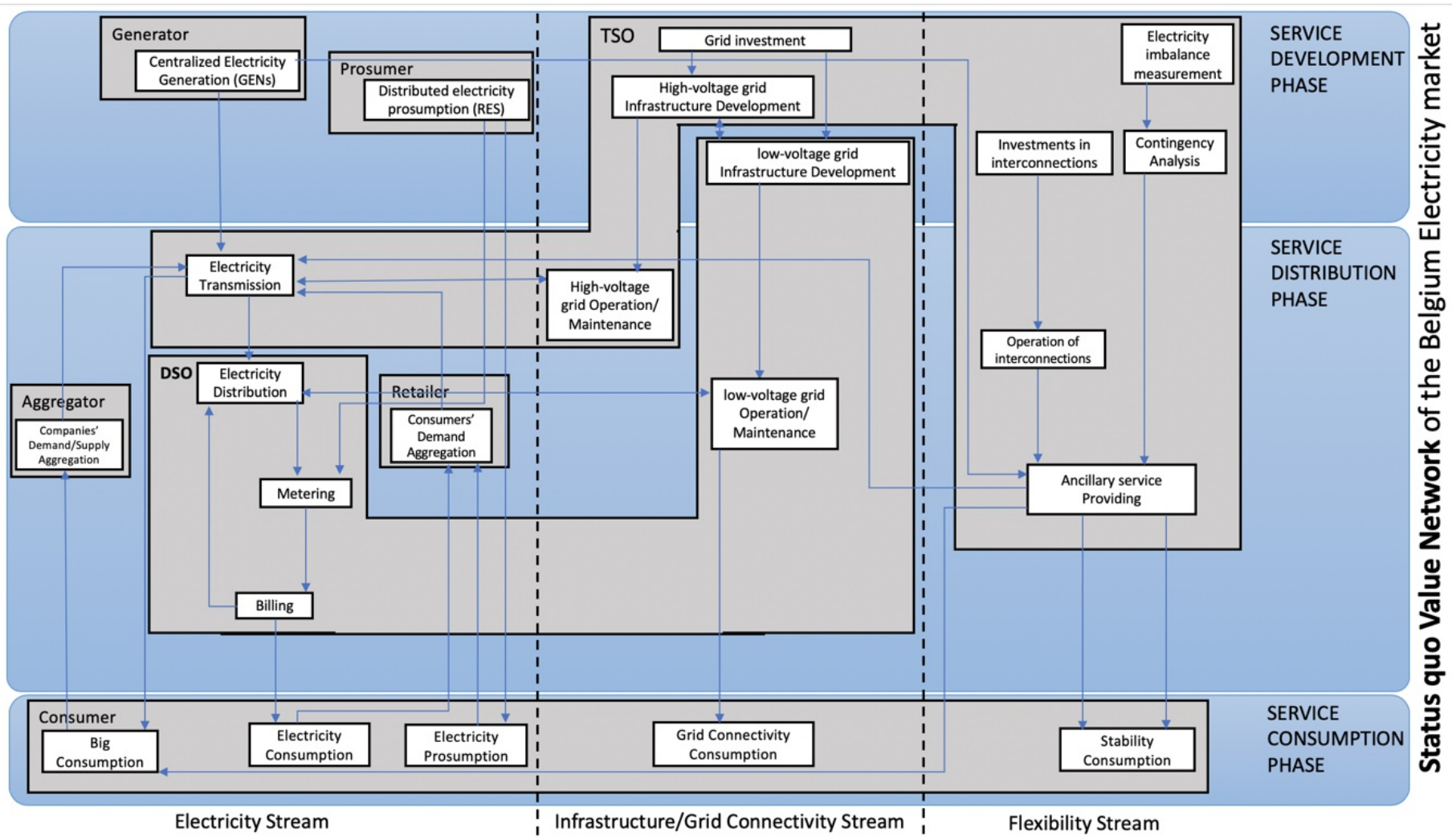

Figure 2. Roles in the current electricity market. Reprinted from New Roles in Peer-toPeer Electricity Markets: Value Network Analysis, by Montakhabi et al., 2020, retrieved from https://www.esat.kuleuven.be/cosic/publications/article-3151.pdf.

trustworthy to undertake roles with sensitive data?" Whoever they are, trustworthiness is a necessity.

A broker is a new role in the P2P electricity market in Flanders. A broker is an intermediate actor that facilitates electricity trading in the P2P market. Brokers have access to information and transactions of all the parties involved in $\mathrm{P} 2 \mathrm{P}$ trading. Their main objective is to facilitate the $\mathrm{P} 2 \mathrm{P}$ market while respecting the electricity grid's constraints, as well as prosumers' preferences and privacy. A broker can be a single point of failure because it has information on all participants in a P2P trading market. Hackers may thus target a broker to steal information about participants in that P2P market (Montakhabi et al., 2020).

\section{Role of Governments and Trust in Governments}

Governments have been the sole player in the electricity market for a long time (and are still in some countries). The electricity market has experienced several steps towards liberalization and some tasks have been delegated by governments to competitive enterprises. Yet still, there are critical roles in the hands of governments (Erdogdu, 2014). The main actors in the current electricity market's value network are prosumers/consumers, retailers, aggregators, Distribution System Operators (DSOs), Transmission System Operators (TSOs), and generators (Montakhabi et al., 2020). (See Figure 2)

Value creation in the electricity market can be briefly described as: Generators produce electricity power plants centrally. Centrally generated electricity is transmitted through the transmission grid and then distributed through the distribution grid to consumers at their sites. TSOs and DSOs take care of transmission and distribution grids. They also keep the grids balanced. Consumers freely select their retailer to purchase their required electricity. Aggregators are new players which represent big consumers in various markets (electricity, balancing, etc.) (see Figure 2 for detailed critical activities of actors.

Besides the regulatory role of governments, TSOs and DSOs are governments' footprints in the electricity market's value network. They undertake critical 


\section{Trust, Transparency and Security in the Sharing Economy: What is the Government's Role? Ruben D'Hauwers, Jacobus van der Bank, Mehdi Montakhabi}

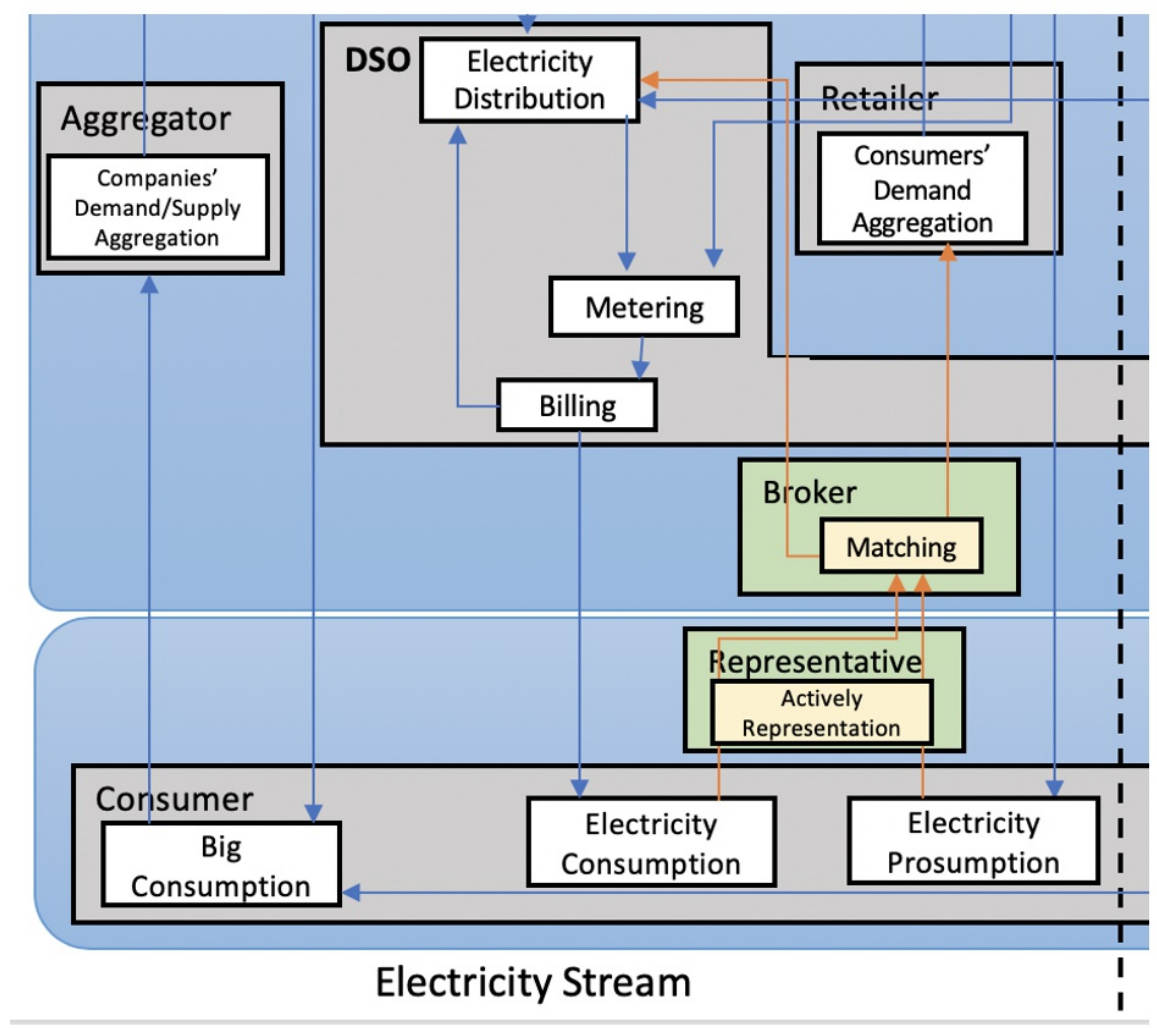

Figure 3. New roles in the near future electricity market. Reprinted from New Roles in Peer-to-Peer Electricity Markets: Value Network Analysis, by Montakhabi et al., 2020, retrieved from https://www.esat.kuleuven.be/cosic/publications/article-3151.pdf.

responsibilities that guarantee the availability and stability of electricity for consumers at any time. Furthermore, they have a monopoly in their tasks, indicating that trust from government in this context is not an option. Despite all the benefits regarding the assurance of service provision and consistency through this relationship, it is a valid concern that the monopoly itself could be a source of threat to misuse of information.

DSOs are already the main single actor with direct access to consumer information within the current electricity grid structure. Considering the required expertise for broker and representative roles in the $\mathrm{P} 2 \mathrm{P}$ trading market, a simple scenario could be that a government (through DSO) extends its responsibilities and undertakes new roles (which would be roll-back liberalisation in the electricity market). In this scenario, DSOs would undertake the role of a broker in the P2P electricity trading market (they could even further extend and take the representative role as well). Figure 3 displays the positions of new roles in the future peer-topeer electricity trading market.
There are some important considerations (pros and cons) which can define the outcome of a government's candidacy with the brokers' (and representatives') role:

\section{PRO}

-DSO has the required technical expertise and experience in dealing with consumers' sensitive information (near real-time pattern, amount of consumption and production).

-DSO is not a profit-seeking organisation, which eliminates the motivation for misuse of trust for financial benefit.

\section{CON}

-Citizens might dislike their information being matched with other information that the government has access to (taxes, income, etc.)

-Extension of the DSO role is in line with monopolisation of a market; this would increase 


\section{Trust, Transparency and Security in the Sharing Economy: What is the Government's Role? Ruben D'Hauwers, Jacobus van der Bank, Mehdi Montakhabi}

the government's footprint in the electricity market and eliminate competition.

-It is more probable to think of the emergence of breakthrough technologies and disruptive innovations if people in the private sector can compete to take this role.

\section{Can Technology Mitigate the Lack of Trust?}

The aforementioned threats, considerations, and lack of trust could be mitigated to some extent by the use of blockchain technology combined with sharing platforms that have P2P electricity trading (Vangulick et al., 2018). From a business perspective, "blockchain is an exchange network for moving transactions, value, assets between peers, without the assistance of [trusted] intermediaries" (Mougayar, 2016). It ensures secure authenticated and accurate transactions by cryptography, and provides a distributed ledger, which keeps all transactions immutable (Murkin et al, 2016). Blockchain technology appears set to help mitigate the lack (or to remove the requirement) of trust amongst involved parties in $\mathrm{P} 2 \mathrm{P}$ markets. Running a platform built on blockchain technology requires a government's willingness to release some of its monopoly in the electricity market in the first place, along with needed investment for setting up the required platform.

\section{Discussion}

An important outcome of the two case-studies is the role of governments. A government could play a key role in creating trustworthiness for the growth of a sharing economy between businesses and peers, as described in table 1.

In the case studies, it was clear that the role of a "neutral" government, without any particular economic motivation, is an important factor in putting the government forward as a trustworthy candidate to ensure trust in sharing economies. An important question arises: "Is the government itself trustworthy?". In both case studies, distrust of the government was observed. This was due to the fact of the government's dual role: on the one hand, government plays the role of a facilitator of data sharing, while on the other hand, it also plays the role of a regulator. Thus, a crucial question arises for determining the role of the government in ensuring trust in the sharing economy: can one guarantee that the government uses data solely for facilitator purposes, or will it also be able to use the same data in its role as a regulator?

Important factors that can overcome this issue are the following:

1. Governments need to clearly divide the role of facilitator and regulator. This can be done by ensuring a public digital platform can exist through its support, but the handling of data can be done by neutral parties. This way, regulating entities at the government would not be able to use the same data.

\section{Governments can ensure trust through} technologies. On one hand, blockchain technology can enable opportunities for distributed trust, where access to data can be limited to certain "permissioned" parties. In digital platforms, technologies can also ensure, with access rights, that the data remains confidential.

Thus, governments can play a significant role in ensuring trust in sharing economies. At the same time, certain limitations need to be put on the government's role, involving access rights to citizen data.

\section{Conclusions and opportunities for further research}

Trust is crucial to enable any sharing economy, of which P2P transactions of value form a key part. In order to enable trust, information as a digital cue is a crucial aspect. The asymmetries of information in the market create bottlenecks to building this trust. Thus, governments can serve to play a role in ensuring trust between actors (B2B, B2C, and $\mathrm{P} 2 \mathrm{P})$. In this paper, we have analysed the adequacy of governments' potential role in enabling trust, transparency, and security in sharing economies based on two case studies. The cases concerned industrial symbioses and P2P electricity trading.

The researchers observed that to define a government's role in ensuring trust, no one-size-fits all answer exists. In the B2B use case, a government could play its role by being an objective facilitator that can mediate between competitive powers in the market. Yet, a government needs to be aware to clearly divide the role of being a facilitator and a regulator. Due to this challenge, digital platforms with clear data access rights are crucial, where a government or government agents may not get access 


\section{Trust, Transparency and Security in the Sharing Economy: What is the Government's Role? Ruben D'Hauwers, Jacobus van der Bank, Mehdi Montakhabi}

Table 1. Case study comparison of the role of the government in ensuring trust in the sharing economy

\begin{tabular}{|c|c|c|}
\hline & $\begin{array}{l}\text { Case } 1 \\
\text { Industrial Symbiosis }\end{array}$ & $\begin{array}{l}\text { Case } 2 \\
\text { Peer-to-peer Electricity Trading }\end{array}$ \\
\hline Role of government & $\begin{array}{l}\text {-Facilitator of data } \\
\text { exchanges } \\
\text {-Regulator }\end{array}$ & $\begin{array}{l}\text {-Current: DSO and TSO } \\
\text { (monopoly) } \\
\text {-Future: Role of a broker } \\
\text {-Dealing with sensitive } \\
\text { information }\end{array}$ \\
\hline $\begin{array}{l}\text { Trust in the } \\
\text { government }\end{array}$ & $\begin{array}{l}\text {-PRO } \\
\text { Neutral role in the } \\
\text { ecosystem } \\
\text { No economic motivation } \\
\text {-CON } \\
\text { Mismatch of the role of } \\
\text { regulator and facilitator } \\
\text { Companies dislike allowing } \\
\text { government access to } \\
\text { sensitive private/personal } \\
\text { information }\end{array}$ & $\begin{array}{l}\text {-PRO } \\
\text { Technical expertise dealing with } \\
\text { sensitive information } \\
\text { No economic motivation } \\
\text {-CON } \\
\text { The risk of a monopoly } \\
\text { Citizens dislike allowing } \\
\text { government access to sensitive } \\
\text { private/personal information }\end{array}$ \\
\hline Technology & $\begin{array}{l}\text {-Digital platform with } \\
\text { privacy enabled settings } \\
\text {-Limiting data access rights } \\
\text { of the government with the } \\
\text { introduction of neutral } \\
\text { partners }\end{array}$ & $\begin{array}{l}\text {-Digital platforms based on } \\
\text { blockchain technology }\end{array}$ \\
\hline $\begin{array}{l}\text { Security/Privacy } \\
\text { threats }\end{array}$ & $\begin{array}{l}\text {-Competitive information } \\
\text { (production process, } \\
\text { volumes of the company) } \\
\text {-Negotiation process (price } \\
\text { information) }\end{array}$ & $\begin{array}{l}\text {-Impersonation } \\
\text {-Data manipulation } \\
\text {-Eavesdropping } \\
\text {-Privacy breaches } \\
\text {-Disputes } \\
\text {-Denial-of-service (DoS) }\end{array}$ \\
\hline
\end{tabular}

to crucial or sensitive private information. In the P2P use case, governments could play an important role. Nevertheless, this comes with the risk that a monopoly position might arise, which could threaten the functioning of the overall ecosystem. The governance of creating a trusted entity could be enabled by introducing a blockchain distributed ledger system with P2P functionality.

In the sharing economy field as a whole, the outcome of the research in this paper suggests that governments can play a significant role. However, that role must always overlap with other roles that need to be identified as well. The major benefit of including the government is its neutral, and often non-competitive position, which can serve to increase market exchanges. Yet, the major hurdles to overcome involve access to data for the government, and the power it gives governments to create new digital monopolies. Technologies such as digital platforms and blockchain can contribute to 


\section{Trust, Transparency and Security in the Sharing Economy: What is the Government's Role? Ruben D'Hauwers, Jacobus van der Bank, Mehdi Montakhabi}

ensuring trust in sharing economies, as they can limit the need for governments to access and handle private data. Blockchain technology and digital platforms are supposed to help mitigate the lack (or in some cases, remove the requirement) of trust amongst active parties. Yet, governments at the same time need to be willing to release their monopolies and control over data access rights in order to overcome this hurdle.

\section{Acknowledgement}

This work was supported in part by the Flemish Government through an FWO SBO project (Mehdi Montakhabi is funded by SNIPPET S007619).

\section{References}

Akerlof, G.A 1970. The Market for "Lemons": Quality Uncertainty and the Market Mechanism, 84, Q.J. Econ., 488.

Amsterdam Sharing City. 2017. Amsterdam Sharing City [website]. Available at: http://www.sharenl.nl/amsterdam-sharing-city (accessed 30 March 2020).

Belk, R. W. 2010. Sharing. Journal of Consumer Research, 36 (5): 715-734

Belk, R.W. 2014. Sharing versus Pseudo-Sharing in web 2.0. Anthropologist, 18: 7-23.

Botsman, R., Rogers, R. 2010. What's Mine is Yours. The Rise of Collaborative Consumption. New York: PH.

Chertow, M.R. 2000. Industrial symbiosis: Literature and taxonomy. Annu. Rev. Energy Environ., 25: 313337.

Christensen J. 1992. The Industrial Symbiosis in Kalundborg, Denmark. Presented at Int. Ind. Conf. Sustainable Dev., Rio de Janeiro

Cook, K., Levi, M., \& Hardin, R. 2009. Whom Can We Trust? How Groups, Networks and Institutions Make Trust Possible. New York, NY: Russell Sage Foundation.

Corritore, C.L., Kracher, B., Wiedenbeck, S. 2003. Online trust: concepts, evolving themes, a model. International Journal of Human Computer Studies, 58 (6): 737-758.

Dasgupta, G. 1988. The Theatricks of Politics. Performing Arts Journal, 11(2): 77.

De Filippi, P. 2017. What blockchain means for the sharing economy. Harvard business review digital articles: $2-5$.

Drexl J. 2017. Designing competitive markets for industrial data- between propitiation and access. JIPITEC 8: 257-292.
Einav, L., Farronato, C., Levin, J. 2016. Peer-to-peer market, The annual review of economics, 2016, 8: 615635

Engberg H. 1993. Industrial Symbiosis in Denmark. New York: New York Univ., Stern Sch. Bus.

Erdogdu, E. 2014. The political economy of electricity market liberalization: a cross-country approach. The Energy Journal, 35(3).

European Commission 2020, Website, Available at: https:/ / ec.europa.eu/digital-single-

market/en/faq/faqs-business-government-data-

sharing, (Accessed 30 March 2020)

European Commission, 2020, Website, Available at : https://ec.europa.eu/environment/europeangreenca $\mathrm{pital} / \mathrm{wp}$ -

content/uploads/2018/05/Industrial_Symbiosis.pdf, Accessed on 30 March 2020

Frenken, K., T. Meelen, M. Arets, and P. van de Glind 2015. 'Smarter Regulation for the Sharing Economy.' The Guardian, 20 May 20. https://www.theguardian.com/science/politicalscience/2015/may/ 20/smarter-regulation-for-thesharing-economy

Frosch RA, Gallopoulos NE. 1989. Strategies for manufacturing. Sci. Am. 266:144-152.

Gefen, D. and Pavlou, P. 2004. The Moderating Role of Conflict on Feedback Mechanisms, Trust, and Risk in Electronic Marketplaces. MIS Quarterly, 1.

Greiner, M., and Wang, H. 2015. "Trust-free systems - a new research and design direction to handle trust issues in p2p systems: the case of bitcoin. In Proceedings of the Americas Conference on Information Systems.

Hamari, J., M. Sjöklint, and A. Ukkonen. 2015. The Sharing Economy: Why People Participate in Collaborative Consumption. Journal of the Association for Information Science and Technology 67 (9): 2047-59

Hawlitschek, F., Teubner, T., Adam, M., Borchers, N., Möhlmann, M., \& Weinhardt, C. 2016. Trust in the sharing economy: An experimental framework. In: Proceedings of the 37th International Conference on Information Systems: 1-14. https://www.lexico.com/en/definition/blockchain, Accessed on 21 April 2020

Investopedia. 2020. Website, Available at: https://www.investopedia.com/terms/s/sharingeconomy.asp , Accessed on 30 march 2020

Javenpaa, S., \& Teigland, R. 2017. Trust in digital environments: From the sharing economy to decentralized autonomous organizations. In: Proceedings of the 50th Hawaii International Conference on Systems Science: 5812-5816.

Kano, L., \& Verbeke, A. 2015. The three faces of bounded reliability: Alfred Chandler and the microfoundations of management theory. California Management Review, 58(1): 97-122. 


\section{Trust, Transparency and Security in the Sharing Economy: What is the Government's Role? Ruben D'Hauwers, Jacobus van der Bank, Mehdi Montakhabi}

Kerber, W. 2016. A new (intellectual) property right for non-personal data? Econ Anal GRUR Int 65:989-998.

Koopman, C., Mitchell, M., Thierer, A. 2015. The Sharing Economy and Consumer Protection Regulation: The Case for Policy Change, $8 \mathrm{~J}$. BUS. ENTREPRENEURSHIP \& L. 529, 533

Luhmann, N. (1979). Trust and Power. Chichester: John Wiley and Sons

Mazzella, F., Sundararajan, A., D’Espous, V., \& Möhlmann, M. (2016). How digital trust powers the sharing economy. IESE Insight, 30: 24-31.

McKnight, D. Harrison and Chervany, Norman L. 2000., What is Trust? A Conceptual Analysis and an Interdisciplinary Model. AMCIS 2000 Proceedings, Paper https://aisel.aisnet.org/amcis2000/382

Möhlmann, M. 2015. Collaborative consumption: determinants of satisfaction and the likelihood of using a sharing economy option again, Journal of Consumer Behaviour, 14 (3): 193-207

Möhlmann, M. 2016. Digital trust and peer-to-peer collaborative consumption platforms: A mediation analysis. Research paper, Leonard N. Stern School of Business, New York University. DOI: $10.2139 /$ ssrn.2813367.

Möhlmann, M., Geissinger, A. 2018. Trust in the sharing economy: Platform-mediated peer trust. In: Handbook on the Law of the Sharing Economy. Cambridge University Press.

Montakhabi, M., Madhusudan, A., van der Graaf, S., Abidin, A., Ballon, P., \& Mustafa, M. A. 2020. Sharing Economy in Future Peer-to-peer Electricity Trading Markets: Security and Privacy Analysis. In Proc. of Workshop on Decentralized IoT Systems and Security (DISS), in conjunction with NDSS: 1-6.

Montakhabi, M., Van Der Graaf, S., Zobiri, F., A. Mustafa, M., Orlando, D., Vanhove, S., Deconinck, G., Schroers, J., Nikova, S. 2020. Secure and Privacy Friendly Peer-to-peer Electricity Trading. SNIPPET: Belgium, 2020 (Report No. D2.1).

Montakhabi, M., Zobiri, F., Graaf, S.V.D., Deconinck, G., Orlando, D., Vanhove, S., et al. 2020. New Roles in Peer-to-Peer Electricity Markets: Value Network Analysis. In IEEE International Energy Conference ENERGYCON.

Mougayar, W. (2016). The business blockchain: promise, practice, and application of the next Internet technology. John Wiley \& Sons.

Murkin, J., Chitchyan, R., \& Byrne, A. 2016. Enabling peer-to-peer electricity trading. In ICT for Sustainability 2016. Atlantis Press.

Mustafa, M. A., Cleemput, S., \& Abidin, A. 2016. A local electricity trading market: Security analysis. In 2016 IEEE PES innovative smart grid technologies conference Europe (ISGT-Europe, IEEE: 1-6.
Nationale Bank België. 2020. Website, Available at: https://www.nbb.be/doc/ts/publications/economicr eview/2018/ecoreviii2018_h3.pdf (Accessed on 30 March 2020)

O’Reilly, T. 2010. Government as a platform. In Open government: Collaboration, Transparency, and Participation in Practice. Lathrop, D., Ruma, L., eds., O'Reilly Media: Sebastopol, CA, USA:11-39.

Opendata Handbook. 2020. Website, Available at: https://opendatahandbook.org/guide/en/what-isopen-data/, Accessed on 30 March 2020

Oxford Reference. 2020. Website, Available at: https://www.oxfordreference.com/view/10.1093/oi/ authority.20110803095959411, Accessed on 30 March 2020

Riegelsberger, J., Sasse, M. A., \& McCarthy, J. D. 2005. The mechanics of trust: A framework for research and design. International Journal of Human-Computer Studies, 62(3): 381-422.

Sundararajan, A. 2016. The Sharing Economy: The End of Employment and the Rise of Crowd-Based Capitalism. Cambridge, MA: MIT Press.

Sztompka, P. 2000. Trust: A Sociological Theory. Cambridge: Cambridge University Press.

Tan, Y., Thoen, W. 2000. Toward a generic model of trust for electronic commerce. International Journal of Electronics Commerce, 5: 61-74

Tseng, M, Tan, A, Chiu, Ch, Tsai, D. 2017. Circular economy meets industry 4.0: Can big data drive industrial symbiosis? Resources, Conservation and Recycling, Vol. 131: 146-147.

Vangulick, D., Cornélusse, B., \& Ernst, D. 2018. Blockchain for peer-to-peer energy exchanges: design and recommendations. In 2018 Power Systems Computation Conference (PSCC), IEEE: 1-7.

Verbeke, A. 2013. International Business Strategy. Cambridge University Press.

Verbeke, A., \& Greidanus, N. 2012. The end of the opportunism versus trust debate: Bounded reliability as a new envelope concept in research on MNE governance. In Handbook of Research on International Strategic Management. Edward Elgar Publishing.

Wiebe, A. 2016. Protection of industrial data - a new property right for the digital economy? GRUR Int., 65: $877-884$.

Williamson, J. 1993. Exchange Rate Management. The Economic Journal, 103(416): 188.

Zucker, L.G. 1986. Production of trust: Institutional sources of economic structure, 1840-1920. Research in Organizational Behavior, 8: 53-111. 


\title{
Trust, Transparency and Security in the Sharing Economy: What is the Government's Role? Ruben D'Hauwers, Jacobus van der Bank, Mehdi Montakhabi
}

\begin{abstract}
About the Authors
Ruben D'Hauwers is a researcher at imec-SMITVUB. He graduated as a Master in Business Engineering at the University of Ghent (2010), and did a second master in Innovation and Entrepreneurship at the Antwerp Management School (2012). He worked as a business developer for AIESEC and SBE in Belgium and Myanmar. Ruben joined imec-SMIT-VUB in 2014 in the field of business model research. His research concerns business models in public-private collaboration in smart cities, in data exchange between stakeholders and business models for sustainable innovations.

Jacobus van der Bank is a researcher at-imec-SMITVUB. He obtained an undergraduate degree in Psychology and a Master's degree in Entrepreneurship at the University of Pretoria (South Africa). After obtaining his Master's degree, and working as a consultant for two years on a variety of projects, he decided to join the academic world where he lectured on entrepreneurship, innovation and business finance at various universities in South Africa. In 2018 he joined SMIT where he is currently working as a business modeller and is responsible for the development of novel business models and commercialisation strategies for projects pertaining to media and the telecommunication domain.
\end{abstract}

Mehdi Montakhabi is a researcher and Ph.D. student at imec-SMIT-Vrije Universiteit Brussel. He studied Bachelor's in Mechanical Engineering, a Master in Entrepreneurship, and a second Master in International Business. His MBA and DBA were in marketing. His current research concerns business model innovation in the energy sector. He worked several years in high-tech firms' marketing management followed by an entrepreneurial experience in the retail sector. He continued his career as the executive manager of a consultancy firm in shopping centre management. He was honoured to be the deputy secretary of the Council of Shopping Centers while directing an educational and analytical monthly magazine in the retail sector.

Citation: D'Hauwers, R., van der Bank, J., Montakhabi, M. 2020. Trust, Transparency and Security in the Sharing Economy: What is the

Government's Role? Technology Innovation Management Review, 10(5): 6-18.

http://doi.org/10.22215/timreview/1352 